\title{
Correlates of Household Food Security in Densely Populated Areas of Southern Ethiopia: Does the Household Structure Matter?
}

\author{
Asefach Hailu and Nigatu Regassa \\ Department of Rural Development and Family Sciences, Hawassa University, \\ P. O. Box 679, Awassa, SNNPR, Ethiopia \\ Telephone: 251-046-2206148, E-mail: negyon@yahoo.com
}

KEYWORDS Correlates; food security; Southern Ethiopia; Sidama and Wolayta Zones; household structure

\begin{abstract}
This article is an empirical study aimed at investigating some socio-demographic correlates of Food Security at household (micro) level in two most populous administrative zones of Southern Ethiopia. The study used primary data which were collected from 788 respondents selected from these two zones using systematic sampling technique. The study incorrorprated twelve independent variables (all of which are related to household sociodemographic structure) in its logistic regression model to see their net effects on household food security status. The study has concluded that seven of the twelve variables included in the model (namely; household size, headship, land size, major sources of household food consumption, marital form, marital status, and age of head of the household) have significant relationship with household food security.
\end{abstract}

\section{BACKGROUND}

Food security is fundamental element in human existence. Without food, nothing happens: no economic growth, no science and technology, no music and literature, not even procreation. Food security, as defined by FAO (1989) is "a state of affairs where all people at all times have access to safe and nutritious food to maintain a healthy and active life". Since the year 1974, when the world was in the midst of food crisis, significant progress has been made towards providing food for reasonably larger number of hungry people. The World Food Conferences of the 1970's and 80's made one of the sweetest declaration of "food for all...... within a decade no child will go to bed hungry, no family will fear for its next day's bread, and no human being's future and capacities will stunted by malnutrition..." Since these declarations, however, the world has faced the most uneven distribution of food (both quality and quantity) ever seen in the history of the world (UN, 1996). Actually, average availability of food (measured as dietary energy supply) is said to increase by over a tenth in the last three decades. During the same period, developing countries recorded increment in food availability by about a fifth. Today, more than any other time in the history of mankind, the volume of poverty and food insecurity coupled with serious malnutrition and morbidities are knocking many doors of the people in most developing world of sub-Saharan African countries.

Ethiopia, as one of the poor nations of the world, is facing repeated macro-and micro level food insecurity coupled with environmental degradation and depletion. In the last three decades, it has not been possible to produce adequate food to meet the needs of the fast growing population, attributed mainly to fragmented land holdings, successive droughts, untimely and unpredictable rainfall, antiquated farm technology, lack of farm input, low producer prices and other ecological factors. On top of this, the fast growing population has forced the practice of unhealthy cultivation systems that deplete the soil; its valuable nutrients and organic matters, promoted erosion that forced the land to loss its productivity. As a result of such poor land management, there has been excessive deforestation without forestation, over cultivation and the like. On the converse, agriculture is the main stay of the country, which supports about $85 \%$ of the population. This subsistence agriculture is actually dependent on the natural resource base of the country. According to several reports and studies, the rural environment of Ethiopia is suffering from heavy land degradation mainly due to recurrent drought and food insecurity, shortage of water and other resource materials that are needed for living. 
Among the nine federal states of the country, the Southern Nations ,Nationalities and Peoples Region (SNNPR), which is the concern of this study, is located in the southern part of the country. With an area of 113,539 square kilometers, it accounts for about 10 percent of the total area of the country. The region constitutes of twelve sub-regional administrative areas called 'Zones' classified on the basis of ethnicity (Sidama, Guraghe, Hadya, Wolaita, Bench Maji, Semen Omo, Debub Omo, Gedeo, Keficho, Kembatta, Alaba Tembaro, and Silti).In the year 2000, the population of the region was estimated at about 12.5 million, of which 6.2 million male and 6.3 million were female population. The region's population accounts for 20 percent of the total population of the country, which makes it the third populous region in the country next to Oromia and Amhara federal states (SNNPR, 2000; CSA, 2000).

The population profile of the region is characterized by large number of children under 15 (46.7 percent) while those in the age group 1564 and above 64 accounts for 50 and 3.3 percent respectively. The median age of the population in the year 2001 was estimated to be about 17 years, which again indicates high prevalence of dependency and high population momentum in the years to come. Out of the total population of the region, women in the reproductive age (1549) account for about 2,970,650 in the year 2000 (47.3 percent of the total female population of the region). Out of these, only 8 percent live in urban areas while 92 percent reside in rural areas of the region.

The region is one of those with uneven distribution of population with crude density of 110.2 persons per square kilometer. The crude birth rates and Total Fertility Rate of the region in recent years was 48.6 and 7 respectively (CSA, 1998). The region is experiencing one of the highest Infant Mortality Rate (113.4 per 1000 live births), under five mortality of 191.5 for both sexes and maternal mortality rate of above 850 per 100,000 live births (CSA, 2000; NOP 2000).About 53.9 percent of children are stunted, 12 percent are severely wasted and 52.5 percent are under weight (CSA, 2000). On top of these, the region exhibits one of the lowest health service coverage in the country (CSA, 1998). Lack of good antenatal delivery, poor postpartum care, malnutrition, anemia, high fertility and the like contributed to the high regional maternal mortality rate.
Moreover, sexually transmitted diseases are among the major health concern of the region. Currently, the HIV cases are increasing very alarmingly and threatening the health status of the citizens and thereby bringing about serious adverse socioeconomic consequences in the region.

In the Southern Nations, Nationalities and People's Region, Enset is the main stay of the people which is source of food and source of income as well. Despite the attractive strategies envisaged by the region to alleviate the problem of food production and security at household level, hunger and malnutrition continue to devastate the majority of the communities in the region. According to a recent estimate, about 59 percent of the households in the region are labelled as food insecured The main determinants of food security, particularly household level relationship between some socio-demographic variables and food security, in Southern Ethiopia are not yet clearly understood and documented.

\section{Objective}

The major objective of this study is to investigate how household level socio-demographic structures affect food security in some densely populated areas of Southern Ethiopia (Sidama and Wolayita administrative zones).

\section{DATA AND METHOD}

The required input data of this study was generated from both primary and secondary sources. As to the primary data, both questionnaire and focus group discussion schedules were used. While the questionnaire is the major source of the primary data, the focus group discussion schedule was used to collect supplementary data on the socio-cultural and environmental impediments of food security and environmental sustainability. As to the secondary data, the study reviewed previous studies conducted in the area and exploited all the available data pertaining to this study.

Sampling: One rationale of collecting huge data in surveys is aimed at making some generalizations and estimations of certain parameters of a study. In order to make sound generalizations about the findings of this study, selection of adequate sample size and following robust procedure was given due attention. Using 
simple method of estimation procedure, the total sample size required for this study was about 600 . However, in order to enhance generalization of the study and keep some contingency for potential non-response, a total sample size of 800 adult men and women for the conventional or quantitative study were selected from the two study areas, Wolaita and Sidama zones, SNNPRG.

The selection of equal sample size from the two study areas was due to the fact that it will be easy and appropriate to compare some parameters of the study. In selecting the desired sample size from the two respective zones, multi stage sampling technique was used. Sampling of the subjects started from preparing the list of woredas and kebeles from the two zones. From a total of 11 woredas in Sidama and eight woredas in Wolaita, only two woredas from each zone were selected using simple random sampling technique. At the second stage of sampling, two kebeles from each selected woreda were taken using simple random sampling technique. At the third stage of sampling, all the households in each kebele were listed and a total sample size of 400 from each stratum (kebele) were taken using systematic sampling technique. For the focus group discussion, 50 community key informants from each of the zones were selected using purposive sampling

The Instrument: In order to generate the required information for this study, two instruments of data collection were developed: The interview schedule and focus group discussion. The interview schedule, which was used as a major source of information, has two major components, namely, household and individual component. It comprises about 55 questions falling under eight sub-sections. The interview schedule helped to elicit information related to the different aspects of the household and individual characteristics including: household demographic and socio-economic characteristics, household food habit and consumption, consumption pattern, household income and expenditure, labour input in agriculture and non-agricultural activities, water source and supplies, household energy, decision making, extension services and participation in environmental protection. The study has also developed a focus group discussion schedule owing to the fact that some deep-rooted sociocultural practices cannot be generated through the use of questionnaire. The focus group discussion had few questions for discussion.
Data Collection: Once the data collection instrument was developed, the first step prior to data collection was the recruitment and training of data collectors. With the aim of enhancing the quality of the data for the study, adequate and quality of data collectors were recruited. The selection and recruitment of these data collectors considered sex, competency, academic, and good command of local language. A total of eight data collectors were recruited and were given a two days rigorous training focusing on practical field experience. Upon the completion of the training session, a pre-test session was arranged on 15 households so that certain potential defects and problems of the questionnaire could be identified prior to the actual fieldwork. During the data collection period, the research team had made every attempt to coordinate, manage and take part in all activities with the aim of maintaining the quality of data.

Data Processing and Analysis: The data were analyzed using both qualitative and quantitative approaches. Information collected through the focus group discussion was analyzed using the qualitative method, as it is very difficult to quantify responses, and was very useful in augmenting the analysis result of the quantitative method. In the quantitative approach, multivariate regression technique (logistic regression) was employed.

\section{RESULTS AND DISCUSSIONS}

Table 1 shows the age distribution of the respondents. It is observed that the majority of the respondents in Wolayta zone are male $(63.5 \%)$ while the female respondents make-up the majority in the case of Sidama zone $(59.8 \%)$. Altogether, the study considered about 410 males and 378 females, giving nearly equal number of respondents from the two sexes. With regard to age distribution of the respondents, attempt was made to randomise and make sound representation of sample subjects from the population concerned. As it shows in the table, the study has taken relatively larger proportion of respondents from prime childbearing age groups (age 25-50) in both Wolayta and Sidama zones. The percentage distribution of respondents in the age group 15-24, 25-34, 35-49, 50-64, and 64 and above are represented by $4.4 \%, 34.9 \%, 38.6 \%$, $16.2 \%, 5.8 \%$ respectively.

Male heads dominantly characterizes the headship status of households in both Wolayta 
and Sidama zones though the case is more pronounced in the Sidama zone. For both zones together, about 25.3 percent of the households are female-headed while the percentage is slightly greater for Wolaita zone (29.3 percent ). Table 1 also indicates the marital status distribution of the respondents, where the majority ( 81.9 percent) in both zones is reported to be currently married, and insignificant proportion of the respondents in the two zones fall in unmarried, divorced and separated category.

It was also important to see the distribution of the respondents by the marital types, that is, whether a household experiences polygamous marriage or not. Accordingly, about 13.5 percent of the respondents in the two zones were reported to have experienced polygamous marriage in which case, the husband has two or more wives at the same time. This figure is nearly equal to the figures reported in DHS survey (2005), which

Table 1: Percentage distribution of respondents by selected Socoi-demographic characteristics

\begin{tabular}{|c|c|c|c|}
\hline \multirow{2}{*}{$\begin{array}{l}\text { Background } \\
\text { variable }\end{array}$} & \multicolumn{2}{|c|}{ Study Zone } & \multirow[t]{2}{*}{ Total } \\
\hline & $\begin{array}{l}\text { Wolayita } \\
(n=400)\end{array}$ & $\begin{array}{c}\text { Sidama } \\
(n=388)\end{array}$ & \\
\hline \multicolumn{4}{|l|}{ Sex } \\
\hline Male & 63.5 & 40.2 & 52.0 \\
\hline Female & 36.5 & 59.8 & 48.0 \\
\hline \multicolumn{4}{|l|}{ Age of Respondents } \\
\hline $15-24$ & 4.5 & 4.4 & 4.4 \\
\hline $25-34$ & 33.5 & 36.3 & 34.9 \\
\hline $35-49$ & 36.3 & 41.0 & 38.6 \\
\hline $50-64$ & 19.5 & 12.9 & 16.2 \\
\hline Above 64 & 6.3 & 5.4 & 5.8 \\
\hline \multicolumn{4}{|c|}{ Headship of the Household } \\
\hline Male & 70.0 & 78.9 & 74.7 \\
\hline Female & 29.3 & 21.1 & 25.3 \\
\hline \multicolumn{4}{|c|}{ Current Marital Status of the Respondents } \\
\hline Married & 78.3 & 85.6 & 81.9 \\
\hline Single & 0.3 & 0.8 & 0.5 \\
\hline Divorced & 1.3 & 0.5 & 0.9 \\
\hline Separated & 4.8 & 0.8 & 2.8 \\
\hline Widowed & 15.5 & 12.4 & 14.8 \\
\hline \multicolumn{4}{|c|}{ Experience of Polygamy Marriage } \\
\hline Yes & 15.0 & 11.9 & 13.5 \\
\hline No & 85.0 & 88.1 & 86.5 \\
\hline \multicolumn{4}{|c|}{ Religious Status of the Respondents } \\
\hline Orthodox & 39.8 & 3.1 & 21.7 \\
\hline Protestant & 56.5 & 85.1 & 70.6 \\
\hline Muslim & 0.5 & 5.2 & 2.8 \\
\hline Adventist & 0.3 & 0.8 & 0.5 \\
\hline Catholic & 2.5 & 5.2 & 3.8 \\
\hline Others & 0.5 & 0.8 & 0.6 \\
\hline \multicolumn{4}{|c|}{ Duration of Stay in the Area of Enumeration } \\
\hline Less than one year & 1.5 & 0.5 & 1.0 \\
\hline $1-5$ years & 1.5 & 1.0 & 1.3 \\
\hline More than five years & s 97.0 & 98.2 & 97.6 \\
\hline Others & - & 0.3 & 0.3 \\
\hline
\end{tabular}

is about 12 percent for the region as a whole. The proportion of households in polygamous marriage for the two zones taken separately reveals that the practice is higher for Wolaita than Sidama zone (15.0 and $11.9 \%$ respectively).

The religious distribution of the respondents reveals that Protestant Christians account for majority of the respondents $(70.6 \%)$ followed by Orthodox Christians (21.7\%). The rest of the religious groups account small proportion. When the two zones are taken separately, orthodox Christians account higher proportion in the case of Wolayta $(39.8 \%)$ compared to the proportion in Sidama (3.1\%). Respondents were also asked to report the number of years they stayed in the place of interview. Accordingly, more than 97 percent of them are found to have lived in the place concerned for more than five years.

\section{CORRELATES OF HOUSEHOLD FOOD SECURITY: MULTIVARIATE ANALYSIS}

This section tries to examine the relationship between selected household socio-demographic variables and state of food security at micro-level in the study area. In order to examine the relative importance or net effect of each independent variable, by controlling all the confounding factors, multivariate analysis in a form of binary logistic regression was employed. The logistic regression technique is used when the dependent variable is dichotomous (binary) in which case the event either " occurs" or " does not occur". In this study, the dependent variable is "household food security" where a household falls in one of the two categories: a household is either "food in secured " or "food secured".

In logistic regression, it directly estimated the probability of an event occurring. For more than one independent variable, that is, for $\mathrm{k}$ independent variables $\left(\mathrm{x}_{1}, \mathrm{x}_{2} \ldots \mathrm{x}_{\mathrm{k}}\right)$, the model can be written as:

$\Pi(\mathrm{X})=\left\{\operatorname{EXP}\left(\beta_{0}+\sum \beta_{\mathrm{I}}^{*} \mathrm{X}_{\mathrm{I}}\right)\right\} /\left\{1+\operatorname{EXP}\left(\beta_{0}+\sum \beta_{\mathrm{I}}^{*} \mathrm{X}_{\mathrm{I}}\right)\right\}$ ..............eq(1) $\mathrm{I}=1,2, \ldots \ldots \mathrm{k}$.

Derivation of the logit model can be performed as follows.

Let $\mathrm{p}=\mathrm{P}(\mathrm{X})$ and $\mathrm{Z}=\left(\beta_{0}+\Sigma \beta_{\mathrm{I}}^{*} \mathrm{X}_{\mathrm{I}}\right)$.

Substituting for eq(1) would result

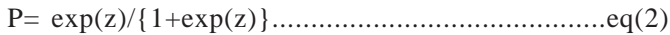

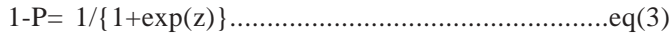

$\mathrm{P} / 1-\mathrm{p}=\exp (\mathrm{z})=$ odds......................................eq(4)

Taking the natural logarithm of the above would result: 


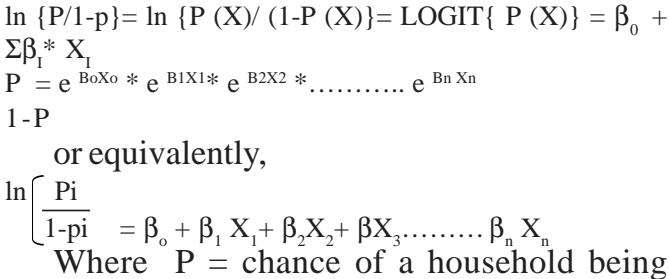
insecured (i.e probability of the event occurring)

$1-\mathrm{P}=$ chance of a household for not being food insecured (i.e probability of an event not occurring)

$\mathrm{Ln} \mathrm{Pi}=$ is the probability or risk of the event occurring which is the odds $1-\mathrm{Pi}$ of household food insecurity.

$\mathrm{Xi}=\mathrm{X}_{1}, \mathrm{X}_{2}, \mathrm{X}_{3}, \mathrm{X}_{4} \ldots \ldots \ldots \mathrm{xn}$ are the independent variables used in the model.

$\beta i=\beta_{1}, \beta_{2}, \beta_{3}, \beta_{4} \ldots$ bn are the regression coefficients indicating the magnitude of change (increased or decreased risk) in the independent variable.

In logistic regression, the parameters of the model are estimated using the maximum likelihood method. That is, the coefficients that make our observed result "likely" are selected. In the logistic regression model, estimates of relative risk is computed either based on the odds ratios (which is defined as the ratio of the probability that the event will occur to the probability that it will not; $\mathrm{P} / 1-\mathrm{p}=\mathrm{e}^{\mathrm{b} *} \mathrm{e}^{\mathrm{b} \mathrm{X}} * \mathrm{e}^{\mathrm{b} \mathrm{X}}{ }_{\mathrm{n}}$ ) or $\log$ of odds ratio (which is defined as the logarithm or logit of the ratio of the probability that the event will occur to the probability that it will not occur; $\log$ $\left.(P)=\beta_{0}+\beta_{1} x_{1}+\beta_{2} x_{2} \ldots \beta_{n} x_{n}\right)$.

Since it is easier to think of odds, rather than log odds, this study will use the odds ratio through out interpreting the relative risk of each independent variable. In the odds ratio, $\mathrm{e}^{\mathrm{i}}$ is the factor by which the odds change when the $i^{\text {th }}$ independent variable increases by one unit. If $b_{I}$ is positive, this factor will be greater than one, which means that the odds are increased (increased risk of household food insecurity), If $b$ is negative, the factor will be less than one $\left(e^{\text {bi }}<1\right)$, which means that the odds are decreased (decreased risk of outcome); when b is zero, the factor equals one $\left(e^{b i}=1\right)$ which leaves the odds unchanged.

Table 2 provides seven predictors, out of the twelve variables, which were initially included in logistic regression model, and are found to have significant relationship with the response variable. The dependent variable (household food
Table 2: Results of logistic regression for the effects of selected socio-demographic variables on household food security $(n=788)$

\begin{tabular}{|c|c|c|c|}
\hline Variables & $\beta$ & SE & $\operatorname{Exp}(\beta)$ \\
\hline \multicolumn{4}{|l|}{ Age of Household Head } \\
\hline $15-24^{\mathrm{RC}}$ & - & - & - \\
\hline $25-34$ & 0.443 & 0.566 & $1.56 *$ \\
\hline $35-49$ & 0.153 & 0.389 & $1.17 *$ \\
\hline $50-64$ & 0.302 & 0.383 & $1.35 *$ \\
\hline $64+$ & -0.216 & 0.405 & $0.81 *$ \\
\hline \multicolumn{4}{|l|}{ Household Size } \\
\hline $0-3^{\mathrm{RC}}$ & - & - & - \\
\hline $4-6$ & 0.332 & 0.453 & $0.21 *$ \\
\hline $7+$ & 0.432 & 0.333 & $0.31 * *$ \\
\hline \multicolumn{4}{|c|}{ Land Size } \\
\hline Less than half hecta & $\mathrm{re}^{\mathrm{RC}}$ & - & - \\
\hline Half to one hectare & 0.340 & 0.510 & $1.405 * *$ \\
\hline Greater than 1 hecta & $\operatorname{are} 0.634$ & 0.560 & $-1.884 * *$ \\
\hline \multicolumn{4}{|c|}{ Headship } \\
\hline \multicolumn{4}{|l|}{ Male $^{\text {RC }}$} \\
\hline Female & -0.171 & 0.315 & $0.84 *$ \\
\hline \multicolumn{4}{|l|}{ Marital Status } \\
\hline Married $^{\mathrm{RC}}$ & - & - & - \\
\hline Divorced & -1.540 & 1.481 & $0.214 * *$ \\
\hline Separated & 1.935 & 1.994 & $0.129 * *$ \\
\hline Widowed & -0.618 & 0.538 & $0.540 * *$ \\
\hline \multicolumn{4}{|l|}{ Marital Form } \\
\hline Polygamous $^{\mathrm{RC}}$ & - & - & - \\
\hline Monogamous & -0.132 & 0.263 & $0.88 * *$ \\
\hline \multicolumn{4}{|c|}{ Major Source of Food Supply } \\
\hline Farm ${ }^{R C}$ & - & - & - \\
\hline Purchase & 0.340 & 0.522 & $0.392 *$ \\
\hline Both & 0.634 & 0.562 & $-0.98^{*}$ \\
\hline Constant & 1.495 & 1.403 & 4.460 \\
\hline
\end{tabular}

$\mathrm{N}=788$

$-2 \log$ likely hood ratio $=881.89$

Overall classification $=76.8$

$\beta=$ Regression Coefficient

$\mathrm{SE}=$ Standard Error

$\mathrm{RC}=$ Reference Category

$* *=$ Significant at 0.01

* = significant at 0.05

Twelve Variables were included in the model, but five of them are not found to be significant and thus are not appearing in this table

security) is measured by directly asking the respondents whether or not the household get enough food throughout the year during the reference period of one year. Since it has no value to present five of the insignificant variables (namely: access to saving and credit, religion, livestock ownership, decision making index, participation in off farm activities), the following few paragraphs describe only seven of the twelve predictors.

It is evident from table 2 that the age of the head of the household has significant relationship with the response variable. It is noted that household heads aged 25-34 are 1.56 time more 
likely to be food secured than the reference category (age 15-24). Similarly, household heads in the age group 35-49 and 50-64 are 1.17 and 1.35 times more likely to result in food secured household. On the contrary, households where the heads are above age 64 became 19 percent $\left(\mathrm{e}^{B}\right.$ $=0.81$ ) less likely to be food secured. Looking at the odds ratios, then, household heads in the age group 25-34 have comparatively better chance of having better food secured households. This is actually the age at which an adult in most rural areas of Ethiopia perform better to support a young family.

The relationship between household size and household food security is very significant. It is shown on the table that the risk of food insecurity increases with household size: i.e households with 4-6 members are 79 percent $\left(\mathrm{e}^{B}=0.21\right)$ less likely to become food secured compared to the reference category. Similarly, households with 7+ members are 69 percent $\left(\mathrm{e}^{B} 0.31\right)$ less likely to become food secured. At the household level food insecurity is aggravated by large family sizes in the study communities. The effect of high fertility on food security is an explicit of a vicious cycle, which the parents consider their children as a source of investment for them during old age. The issue here indicates that the opportunity costs needed in bringing up their offspring is not vibrantly analysed. Frequent births have a negative impact on the nutritional and health status of the mothers as well as on families' well being. Furthermore, household and mothering responsibilities also prevent rural women from participating in income generating schemes and extension programs. The interrelated problems of large family sizes of food insecured household is a cause to dependency syndrome and often leads to food aids for feeding many mouths.

The household headship is also another important demographic variable entered into the model. It is seen that households, where females assume headship, are 16 percent $\left(\mathrm{e}^{B}=0.84\right)$ less likely to become food secured. During the survey, it was understood that there are very few cases where females are the head of the household, and this happens when only the husband is absent or dead. In such circumstances, the female head of the household does little to handle all the indoor and out-door activities. Because marriage occurs early in the community, there is less likelihood that another household member handles the out-door activities (agricultural activity) to bring food to the family. The relationship between marital status of respondents and status of household food security seems to follow the expected pattern. It is noted that divorced, separated and widowed respondents are 79 percent, 88 percent, and 56 percent less likely to become food secured respectively.

The relationship between marital form and household food security is also interesting and worth investigating in Ethiopian context since multiple marriages is common in some communities and especially in the study areas. As shown in table 2 , households with polygamous marital union are 12 percent $\left(\mathrm{e}^{\mathrm{B}}=0.88\right)$ less likely to fall into food secured status. Though the polygamous marital form is dwindling down in recent years, there are still good proportions of the households maintaining the values and practices of such family system. As it is true in other parts of Africa, the Polygyny system is practiced in a situation where land and other resources are available in good quantity to a man to establish separate homestead through marrying two or more wires at the same time. In such family system, the wife usually finds more freedom to manage her resources and assets.

The findings of this study have also indicated that the risk of food insecurity increases where a household depends more on food purchase than farm. In rural context where land is the most important household assets and wealth indicator, dependence merely on food purchase risks family members unless other sustainable income source is possible.

\section{CONCLUSION AND POLICY IMPLICATIONS}

As clearly outlined in the first section of this article, the study has primarily aimed at examining how some socio-demographic household characteristic affect the status of household food security. The study has based its analysis on the data collected from 788 respondents who were selected from two most populous administrative zones of southern Ethiopia namely Sidama and Wolayta tribes both of which represent dominant ethnic groups in Southern Ethiopia.

Applying one of the multi-variate statistical analysis, binary logistic regression, the study has found out that some household structures namely; household size, age of household head, headship, marital status, marital form, major source of consumption, operational land size owned have 
significant relationship with household food security status. Other household variables entered into the model (such as decision making index, access to credit and saving, ownership of cattle, participation in off farm activities and the like) were not found to have significant contribution to the dependent variable. Based on the data collected from the 788 households and the analysis made, the following two conclusions and policy implications are drawn:

First, some household structures have significant contribution to food insecurity at household level in the two most populous administrative zones of Southern Ethiopia. It should be noted that population pressure, which is approximated by household size, is known to be one of the leading causes of food insecurity in the study area. This implies that concerted efforts have to be made by the regional government in reducing the high level of fertility (which is estimated as 6 children per woman) or help households increase food production to feed members.

Secondly, with increase in population size of the region, land is becoming very scarce and the farmers are now forced to produce food on small plot of land with poor agricultural technologies. In such circumstances, the current food crisis at both regional and local level persists and might push influx of people to migrate to the nearby urban areas. It is therefore important that the regional government should integrate development of the rural sector, the spread of small-scale industries throughout the countryside, and the reorientation of economic activity and social investments towards rural areas of the region.
Also, diversification of activities through building rural peoples' capacity, introduction of various off-farm activities and facilitation of better market conditions are among the prime recommendations of this study.

\section{ACKNOWLEDGEMENT}

This research work was funded by the HUNORAD project. The authorS thus would like to thank the HU-NORAD project coordinator, Dr. Admasu Tsegaye, for all kinds of assistance during the research period. Also, our heartfelt thanks goes to Dr. Adugna Tollera, the Associate Vice President for Research and Extension Program of the Hawassa University for tirelessly reading and editing the manuscript and keen encouragements.

\section{REFERENCES}

CSA. 1998. The Population and Housing Census of Ethiopia. Results at Country Level Analytical Report, Addis Ababa.

CSA. 2000. The Population Situation of Ethiopia. Country level Analytical Report, Addis Ababa.

FAO. 1989). Women in Developing Agriculture: The State of Food. Rome, Italy.

NOP. 2000. The Population and Development, Addis Ababa. Ethiopia: Ministry of Finance and Economic Cooprations.

SNNPR 2000. The Socioeconomic Profile of Southern Nations, Nationalities and Peoples Region. Awassa, Ethiopia: Regional Office of Population.

U.N. 1996. World Survey on the Role of Women in Development. Report of the Secretary General to the World Conference to Review and Appraise the Achievement of the United Nations Decade for Women: Equality, Development and Peace. 